
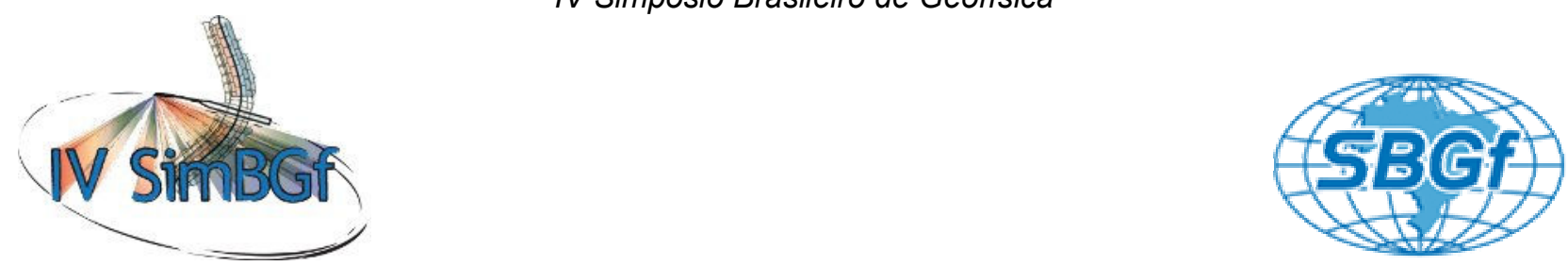

\title{
Aeromagnetometria gradiométrica: conhecimento atual e aplicações na Província Mineral do Tapajós
}

Thais Andressa Carrino, LGA-UnB; Adalene Moreira Silva, LGA-UnB; Nilson Francisquini Botelho, IG-UnB; Marcelo Pinto, Mapex Mineração, Importação \& Exportação Ltda.; Luiz Carlos Pinheiro Clerot, Mapex Mineração, Importação \& Exportação Ltda.

Copyright 2010, SBGf - Sociedade Brasileira de Geofísica

Este texto foi preparado para a apresentação no IV Simpósio Brasileiro de Geofisica, Brasilia, 14 a 17 de novembro de 2010. Seu conteúdo foi revisado pelo Comitê Técnico do IV SimBGf, mas não necessariamente representa a opinião da SBGf ou de seus associados. É proibida a reprodução total ou parcial deste material para propósitos comerciais sem prévia autorização da SBGf.

\section{Resumo}

A aeromagnetometria gradiométrica consiste numa importante ferramenta para detalhamento de feições magnéticas crustais em resolução superior aos dados magnetométricos convencionais. Este artigo aborda o uso de imagens dos gradientes horizontais medidos ( $G x$ e Gy) e produtos calculados como a AGHT e a ASA para caracterização geológico-geofísica de dois prospectos auríferos localizados na Província Mineral do Tapajós. Nesta abordagem, dados geoquímicos de ouro em solo foram integrados com as imagens magnetométricas, sendo possível associar as áreas anômalas de ouro com importantes feições magnéticas, como estruturas de baixo gradiente e diques máficos, este últimos podendo ter atuado como barreira geoquímica à precipitação de ouro.

\section{Introdução}

A magnetometria aérea vem avançando na melhoria da aquisição e qualidade dos dados, destacando-se dentre outros fatores empregados, a determinação de linhas de vôo menos espaçadas e obtenção de medidas de gradientes e do campo magnético total, estas últimas permitindo a coleta de dados com maior resolução e detalhamento de feições magnéticas rasas (Thompson et al., 2007).

A indústria de exploração de óleo e gás incentivou o uso dos primeiros gradiômetros magnéticos aéreos, objetivando aumentar a resolução dos dados, o que implica na melhoria da caracterização estrutural de bacias produtoras. Dois, três e mais recentemente quatro sensores dispostos nas asas e cauda de aviões compreendem as configurações mais utilizadas. Com o uso de quatro sensores, é possível medir o gradiente vertical que, juntamente com os gradientes horizontais, são utilizados para o cálculo de profundidade de fontes magnéticas com maior acurácia (McMullean e MacLellan, 1997; Reford, 2006).

Este artigo explora o uso de dados magnetométricos gradiométricos visando a caracterização dos prospectos auríferos 12 de Outubro e Rosa de Maio, ambos inseridos na porção oeste da Província Mineral do Tapajós (Figura 1). Estas regiões são estratégicas pois configuram importantes fronteiras exploratórias na região amazônica, ainda carente de maiores detalhamentos geológicos para viabilização de projetos de mineração.

O prospecto 12 de Outubro (Figura 1) caracteriza-se por rochas relacionadas com o Grupo Iriri, como riolitos e brechas hidrotermais. A alteração hidrotermal predominante é a silicificação, que gera uma diminuição da concentração de potássio nas rochas mineralizadas, conforme mostrado em gráfico da razão de $\mathrm{K}_{2} \mathrm{O} / \mathrm{SiO}_{2}$, produzido com base em dados obtidos por geoquímica de rocha (Pinto et al., 2009). Adicionalmente, estes autores mostram que as concentrações de ouro nas amostras analisadas possuem relação direta com aumento de $\mathrm{SiO}_{2}$ e diminuição de $\mathrm{K}_{2} \mathrm{O}$.

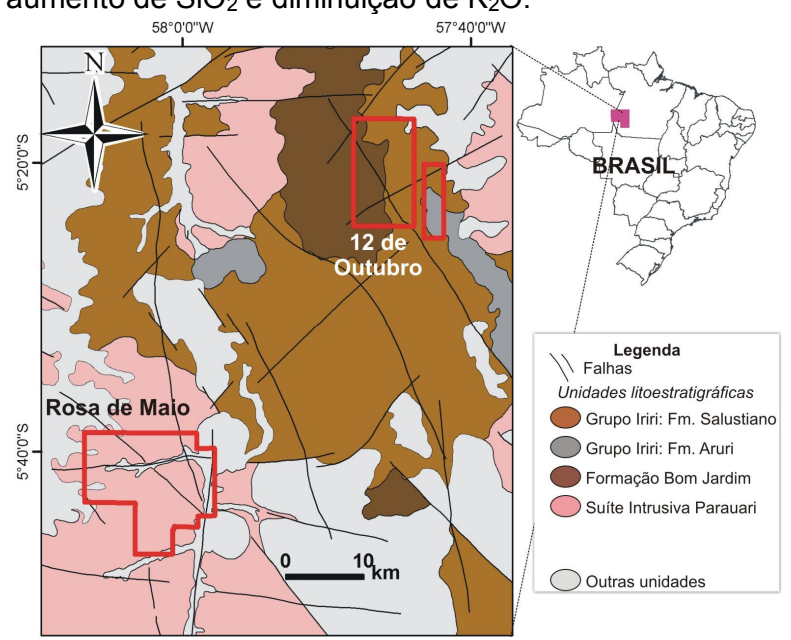

Figura 1. Localização dos prospectos 12 de Outubro e Rosa de Maio na Província Mineral do Tapajós e mapa geológico simplificado (modificado de Klein et al., 2001).

Os granitos da Suíte Intrusiva Parauari da região do prospecto Rosa de Maio (Figura 1) caracterizam-se por assinatura geoquímica de granitos pós-colisionais (Pinto et al., 2009). No setor central deste prospecto, as rochas dominantes caracterizam-se por composição monzogranítica e, localmente, há afloramentos de quartzo diorito. As mineralizações auríferas estão hospedadas em veios de quartzo de alto teor (108 $\mathrm{g} / \mathrm{t} \mathrm{Au})$ e em granitos Parauari hidrotermalizados (6 g/t Au). A alteração hidrotermal predominante compreende a sericitização, seguida da silicificação, conforme 
evidenciado pelas maiores razões de $\mathrm{K}_{2} \mathrm{O} / \mathrm{SiO}_{2}$ obtidas por geoquímica de rocha (Botelho et al., 2009; Pinto et al., 2009).

\section{Aeromagnetometria gradiométrica}

Diferentemente de levantamentos magnetométricos convencionais, o uso de dados relacionados com medidas magnetométricas gradiométricas permite 0 detalhamento de feições geofísicas através do emprego de, pelo menos, mais de um sensor a bordo de uma plataforma aérea, permitindo a medição de gradientes horizontais e/ou verticais.

Um gradiente é medido para encontrar a diferença entre duas leituras de magnetômetros. Quando normalizado com respeito à separação dos sensores, a diferença forma um gradiente na direção da linha entre os dois sensores. Genericamente, um gradiente $G$ é dado pela Eq. 1:

$$
\frac{\partial G}{\partial \mathrm{h}}=\frac{\left(\mathrm{G}_{2}-\mathrm{G}_{1}\right)}{\Delta \mathrm{h}},
$$

onde $G_{1}$ e $G_{2}$ são as leituras dos magnetômetros e $\Delta h$ consiste na separação dos mesmos (Telford et al., 1990).

O objetivo de medidas de gradientes ou mesmo o cálculo de derivadas é resolver as componentes vetoriais individuais do campo magnético. Em uma configuração de três sensores, a normal do vetor ao plano dos sensores não pode se exclusivamente resolvida, havendo a necessidade de definir o vetor campo total com um conjunto de quatro sensores. Ou seja, na configuração de três sensores, apenas os gradientes longitudinal (Gy) e lateral $(\mathrm{Gx})$ no plano dos três sensores são medidos e $\mathrm{Gz}$ é calculado, não sendo possível resolver as três componentes do campo total. Entretanto, é possível obter gradientes não medidos do campo total utilizando as transformações de Fourier ou de Hilbert. Todavia, estes processos necessitam de um conhecimento a priori sobre a geometria do corpo/fonte. Em função destas limitações teóricas, recomenda-se fortemente a medida dos três gradientes ortogonais simultaneamente, ou seja, usando quatro sensores (McMullean e MacLellan, 1997).

A gradiometria proporciona melhora na discriminação de anomalias rasas, além da minimização de efeitos de variação diurna do campo magnético terrestre, principalmente em latitudes magnéticas altas (Telford et al., 1990). De acordo com McMullean e MacLellan (1997) e Schmidt e Clark (2006), as principais considerações a respeito da magnetometria gradiométrica compreendem: (a) medidas de gradientes não sofrem influência do campo magnético de background, ou seja, aquele relacionado com o núcleo da Terra. Por tal, apenas as componentes de alta freqüência são registradas, o que implica em dados relativos ao nível mais crustal da Terra e que são os de maior interesse à exploração de recursos naturais; (b) há a redução da necessidade de correções regionais que são requeridas para levantamentos convencionais de campo magnético total; (c) há maior resolução que levantamentos convencionais que usam um único sensor, além da melhora na definição de feições subparalelas às linhas de vôo e de fontes alongadas na direção N-S em baixas latitudes; (d) o uso de gradientes medidos permite o cálculo de parâmetros com resolução superior e acurácia, como uso dos gradientes para deconvoluções do tipo Euler.

Kurimo e Multala (1995) utilizaram dados magnetométricos gradiométricos na Finlândia, e observaram a alta precisão de informações magnéticas, além da melhora da qualidade dos dados interpolados. Comparações de dados provenientes de gradientes horizontais medidos com dados coletados por um único sensor magnetométrico mostraram a qualidade superior dos primeiros.

A principal limitação na precisão de gradientes medidos compreende os efeitos magnéticos da aeronave. Com o melhor registro do movimento da aeronave, principalmente em vôos turbulentos, e medidas da resposta magnética estática da aeronave, a compensação pode ser melhorada por meio de pósprocessamento para remover a resposta do sistema (McMullean e MacLellan, 1997).

\section{Materiais}

Os dados geofísicos são referentes aos aerolevantamentos efetuados nos prospectos 12 de Outubro e Rosa de Maio (Figura 1), realizados, respectivamente, entre 17 e 30 de Janeiro de 2006 e entre 7 e 15 de Janeiro de 2006. Os dados coletados compreenderam o tipo aeromagnetométrico gradiométrico e o aerogamaespectrométrico, e foram adquiridos pela empresa Lasa Engenharia e Prospecções S.A. A altura de vôo foi mantida constante em $100 \mathrm{~m}$, e as linhas de vôo $(\mathrm{N}-\mathrm{S})$ e de controle $(\mathrm{E}-\mathrm{W})$ variaram, respectivamente, da seguinte maneira: para o bloco 12 de Outubro consistiram em $100 \mathrm{~m}$ e $4000 \mathrm{~m}$, e para o bloco Rosa de Maio consistiram em 75 m e 750 m (Lasa Engenharia e Prospecções S.A., 2006a, b).

A aeronave utilizada foi uma Cessna, modelo 208-Grand Caravan, com o prefixo PT-MEP. Corresponde a um modelo turbo-hélice monomotor, com velocidade média de $255 \mathrm{~km} / \mathrm{h}$. O aeromagnetômetro é formado por três sensores de vapor de césio Scintrex, modelo CS-3, com resolução de 0,001 $\mathrm{nT}$, para registro de dados do campo magnético total e dos gradientes horizontais lateral $(\mathrm{Gx}) \mathrm{e}$ longitudinal (Gy). A taxa de amostragem equivaleu a 20 $\mathrm{Hz}$. Vinte leituras de dados do magnetômetro foram realizadas a cada segundo (Lasa Engenharia e Prospecções S.A., 2006a, b). O cálculo dos gradientes medidos, Gx e Gy, foi efetuado pela Lasa Engenharia e Prospecções S.A. (2006a, b). O gradiente lateral (Gx) representa a diferença dos valores medidos nos dois sensores presentes nas asas da aeronave, sendo este valor dividido pela respectiva distância entre os mesmos $(15,70 \mathrm{~m})$. Já o gradiente longitudinal (Gy) equivale à média dos valores registrados pelos sensores localizados na asa da aeronave, posteriormente subtraída do valor adquirido pelo sensor da fuselagem. Este resultado foi dividido pela distância entre a localização dos sensores 
da asa e o da fuselagem (12,70 m) (Lasa Engenharia e Prospecções S.A., 2006a, b).

Dados geoquímicos disponíveis e referentes à concentração de ouro em solo compreendem aqueles cedidos pela empresa Mapex Mineração, Importação e Exportação Ltda. para a área do prospecto 12 de Outubro (739). Análises para ouro em solo foram realizadas pelo método Fire Assay (fusão e copelação), sendo que 34 amostras foram analisadas por ICP-MS para 34 elementos. Estas análises foram realizadas, respectivamente, pela Lakefield Geosol e ALS Chemex. Para o prospecto Rosa de Maio, foram utilizados 560 dados de geoquímica de ouro em rocha.

\section{Abordagem metodológica}

Os valores do IGRF foram subtraídos dos dados de campo magnético total, resultando no campo magnético anômalo (CMA). Em seguida, procedeu-se à averiguação de perfis rebatidos do CMA para análise de possíveis inconsistências, como valores altamente anômalos, por meio do cálculo da diferença quarta e parâmetro $P$ (Blum, 1999). Neste sentido, nenhuma inconsistência não justificável foi observada.

Testes de interpolação dos dados do campo magnético anômalo e dos gradientes medidos foram realizados e, qualitativamente, observou-se que o método bi-direcional (spline Akima) aparentou melhores resultados, pois ruídos na direção das linhas de vôo foram mais atenuados em relação ao resultado produzido pelo método curvatura mínima. $O$ passo seguinte correspondeu à efetivação do micronivelamento dos dados, seguindo-se a metodologia proposta por Minty (1991).

Células de $15 \mathrm{~m}$ e $25 \mathrm{~m}$ foram selecionadas aos dados dos prospectos Rosa de Maio e 12 de Outubro,

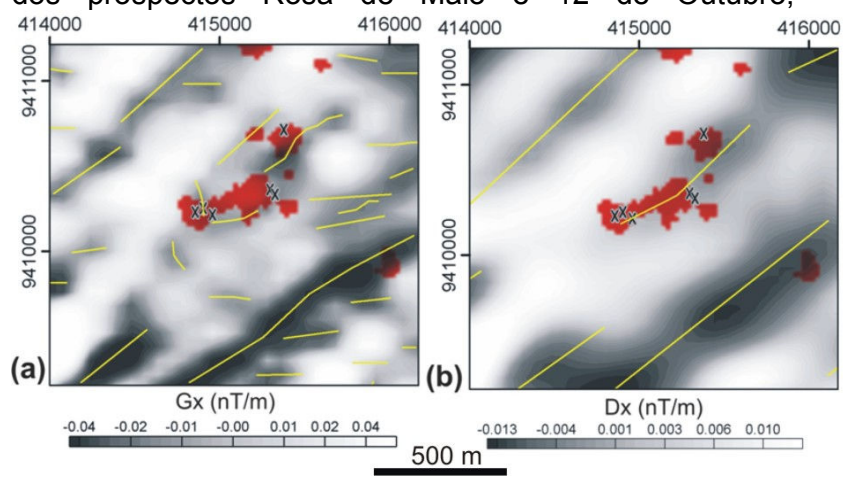

respectivamente. Além das imagens dos gradientes medidos, procedeu-se também ao cálculo da AGHT com base nos dados de Gx e Gy, e com base nas derivadas horizontais em $x$ e y (Dx e Dy). A AGHT permite, simplificadamente, determinar as bordas dos corpos magnéticos (Graunch e Cordell, 1987). Destaca-se que as imagens de derivadas calculadas tiveram de ser filtradas por meio do uso do filtro de convolução hanning 3x3 para suavizar ruídos N-S (direção das linhas de vôo). No caso dos gradientes horizontais medidos, tais ruídos não foram observados, e a filtragem foi dispensada.

Dados geoquímicos de ouro em solo disponíveis ao prospecto 12 de Outubro foram processados por meio da simulação indicatriz seqüencial. Foram empregados 15 passos de $50 \mathrm{~m}$, tolerância do passo de $5 \mathrm{~m}$, considerando a produção de variograma experimental na direção de maior variabilidade $(245 \mathrm{Az}$.), e geradas 500 imagens simuladas. Optou-se pela produção da imagem da média das 500 simulações e posterior cálculo do corte de $25 \%$ de probabilidade de ocorrência da variável indicatriz ouro em solo, de forma a ressaltar as áreas mais anômalas neste metal.

As imagens magnetométricas foram analisadas individualmente e/ou integradas com a imagem de teor de ouro em solo ou com os dados pontuais de teor de ouro em rocha, conforme mostrado nas figuras $2,3,4$ e 5.

\section{Resultados}

\section{Prospecto 12 de Outubro}

A comparação de imagens dos gradientes horizontais medidos Gx e Gy, das primeiras derivadas horizontais do campo magnético anômalo (Dx e Dy) e da AGHT (Figuras 2 e 3), permite as seguintes observações:
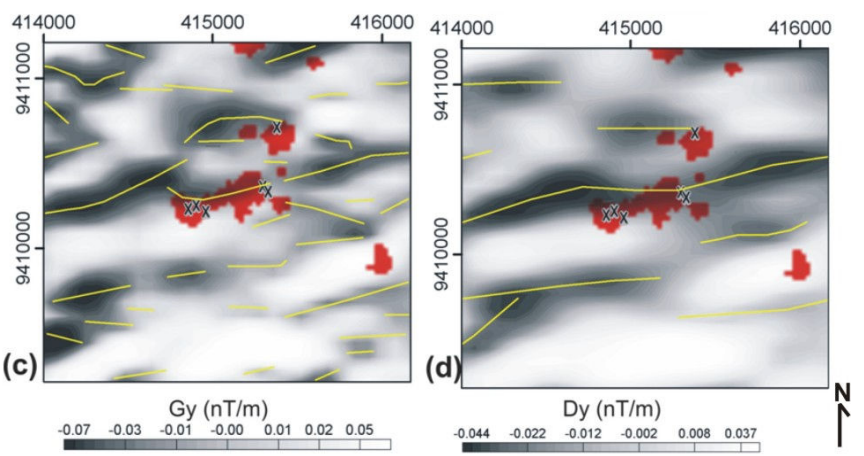

Figura 2. Comparação de produtos magnetométricos integrados com a imagem de probabilidade de ocorrência da variável indicatriz ouro em solo maior que 25\%: (a) imagem do gradiente medido Gx; (b) imagem da primeira derivada horizontal em $x$ do campo magnético anômalo; (c) imagem do gradiente medido Gy; (d) imagem da primeira derivada horizontal em y do campo magnético anômalo. Observar maior resolução das feições de baixo gradiente proporcionada pelas imagens de $\mathrm{Gx} e$ Gy em relação às imagens calculadas das respectivas derivadas. Cruzes indicam os pits e ocorrências de ouro.

(a) as imagens de gradientes medidos apresentam melhor definição das feições de baixos gradientes em relação às respectivas imagens calculadas a partir das derivadas horizontais de primeira ordem do campo magnético anômalo, fazendo-se jus às considerações apresentadas em McMullean e MacLellan (1997) e Schmidt e Clark (2006). Da mesma forma, a imagem da AGHT calculada a partir do uso dos gradientes Gx e Gy refinam com maior acurácia as estruturas presentes na 
área em relação à imagem da $\mathrm{AGHT}$ calculada a partir das derivadas Dx e Dy;

(b) as integrações das imagens referentes à geoquímica de ouro em solo $e$ as magnetométricas foram estabelecidas de forma a proporcionar a observação de padrões e feições associáveis com as anomalias auríferas. Tal padrão é claramente verificado por meio da integração das principais feições interpretadas na imagem do gradiente horizontal medido na direção y (Gy) (que ressalta as estruturas mais próximas da orientação E-W e que são muito importantes no contexto deste prospecto) com imagens das anomalias de ouro (Figura 2). Nota-se que para a imagem de corte de probabilidade de ocorrência da variável indicatriz ouro em solo maior que $25 \%$, as seis ocorrências auríferas do prospecto 12 de Outubro estão relacionados com anomalias auríferas com continuidade ENE-WSW, compatível com o lineamento interpretado com base na imagem do gradiente medido Gy. Estas feições ENE-WSW devem representar um sistema de fraturas ou falhas rúpteis associado com o contexto das mineralizações de ouro. Por tal, constituem uma importante zona de influência metalogenética para a prospecção aurífera nesta região (Klein et al., 2001);
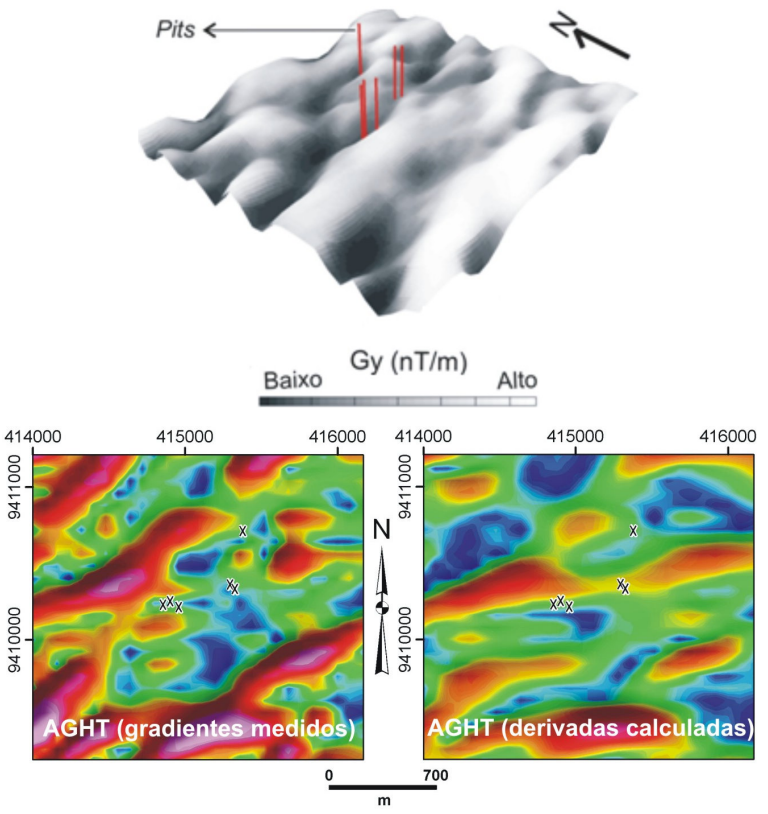

Figura 3. Disposição em $2.5 D$ da imagem do gradiente medido Gy e pits do prospecto 12 de Outubro. Também são apresentadas as imagens da AGHT resultante do cálculo com base no isso dos gradientes horizontais medidos e com base nas derivadas horizontais calculadas. Cruzes indicam os pits e ocorrências de ouro. Cores quentes indicam altos valores da AGHT; cores frias, baixos valores.

(c) na imagem do gradiente Gx, é possível observar também correlações das anomalias auríferas com baixos gradientes que indicam a variação lateral de tais feições. A disposição da imagem do gradiente medido Gy em 2.5
D apresentada na figura 3 , permite a observação mais clara da localização dos pits dos prospectos 12 de Outubro em concordância com os baixos gradientes ENE-WSW.

\section{Prospecto Rosa de Maio}

A comparação das imagens dos gradientes medidos Gy e $\mathrm{Gx}$, das derivadas horizontais de primeira ordem do campo magnético anômalo (Dy, Dx), e da AGHT está mostrada na figura 5 , considerando-se as principais áreas prospectivas do Rosa de Maio, conforme indicado na figura 4. A partir da figura 5 , é possível verificar as seguintes relações:

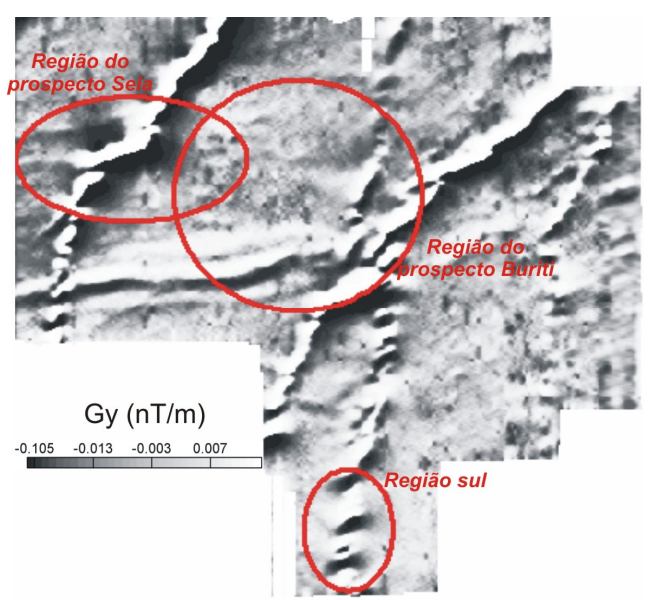

Figura 4. Imagem do gradiente horizontal em y medido do prospecto Rosa de Maio e indicação das três áreas analisadas em detalhe, e que estão referidas na figura 5.

(a) as imagens dos gradientes horizontais medidos (Gy e Gx) são capazes de revelar feições magnéticas de maneira superior às suas imagens equivalentes calculadas por meio das derivadas de primeira ordem do campo magnético anômalo (Dy e Dx);

(b) em todas as imagens magnetométricas, fica claro que os maiores valores de ouro em rocha estão correlacionados com a proximidade espacial da região do enxame de diques máficos (prospectos Sela e Buriti), além das estruturas E-W e NE-SW, predominantemente;

(c) os diques máficos aparentam estar deformados e segmentados. Estes diques, denominados Diabásio Piranhas (cf., Santos et al., 2002), fazem parte de um extenso enxame que foi datado por Santos et al. (2002) pelo método U-Pb em badeleíta, derivando a idade de cerca de $510 \mathrm{Ma}$. Desta maneira, subentende-se que estas intrusões máficas são de uma época pósmineralização paleoproterozóica e, desta forma, não possuem uma contemporaneidade para terem atuado como barreira geoquímica à precipitação do ouro. As intrusões, inclusive, devem ter sido favorecidas pelas estruturas pré-existentes, como as de direção E-W, NESW e NNE-SSW (algumas das quais podem ter tido um papel importante à percolação de fluidos hidrotermais para a origem das mineralizações). Um papel que pode estar associado aos diques consiste em uma possível 
remobilização do ouro paleoproterozóico (cf., Juliani 2007, inédito), o que poderia explicar a tão evidente associação das anomalias auríferas em rocha com esta unidade máfica. Entretanto, mais trabalho é necessário para determinar se todos ou a maioria dos diques deste enxame possuem a mesma idade obtida por Santos et al. (2002);

(d) a deformação dos diques parece ter sido derivada de, pelo menos, duas ativações tectônicas na região, visto pelo registro de movimentação sinistral e dextral nas áreas analisadas em detalhe (Figura 5). Destaque é dado à imagem da AGHT produzida a partir das imagens de Gx e Gy na porção sul do Rosa de Maio pois, em relação à imagem da AGHT calculada com base nas derivadas Dx e Dy, é possível observar claramente sigmóides dextrais que registram a deformação do dique máfico.

\section{Conclusões}

As imagens magnetométricas gradiométricas e os produtos derivados do uso de tais gradientes (e.g., AGHT), permitem um avanço significativo no reconhecimento de feições magnéticas crustais, algumas das quais, podem ter papel relevante na gênese de mineralizações. A partir deste artigo, fica expresso que estes dados são superiores, em termos de resolução, quando comparados aos dados magnetométricos convencionais, mas que ainda é preciso utilizar, nos programas de levantamentos nacionais, um sistema triaxial para a obtenção dos gradientes $\mathrm{Gx}, \mathrm{Gy}$ e $\mathrm{Gz}$. Este arranjo de quatro sensores permite a obtenção de produtos como a Amplitude do Sinal Analítico e deconvoluções (e.g., Euler) com maior acurácia de resolução. Esta possibilidade de melhor caracterização geológico-geofísica é muito importante para a determinação detalhista de feições magnéticas associadas com alvos metalogenéticos.

\section{Agradecimentos}

Agradecemos à UnB pelo suporte técnico, ao CNPq pelo projeto CT-Mineral ( $\left.n^{\circ} .555063 / 2006-2\right)$ e à CAPES pela bolsa de mestrado. A.M. Silva e N.F. Botelho agradecem ao $\mathrm{CNPq}$ pelas respectivas bolsas de produtividade em pesquisa.

\section{Referências}

Blakely, R.J. 1996. Potential theory in gravity \& magnetic applications. Cambridge, Cambridge University Press. $441 \mathrm{p}$.

Blum M.L. 1999. Processamento e interpretação de dados de geofísica aérea no Brasil central e sua aplicação à geologia regional e à prospecção mineral. Tese (Doutorado em Geologia) - Universidade de Brasília, Brasília-DF, 229 p.

Botelho N.F., Pereira K.M.S., Moura M.A., Clerot L.C., Pinto M., Lopes G.C. 2009. Geoquímica e inclusões fluidas das mineralizações auíferas dos prospectos Doze de Outubro e Rosa de Maio, Província Aurífera Tapajós,
Amazonas. In: II Simpósio Brasileiro de Metalogenia, Gramado, Anais....SBG, em CD-ROM.

Graunch, V.J.S., Cordell, L. 1987. Limitations of determining density or magnetic boundaries from the horizontal gradient of gravity or pseudogravity data. Geophysics, 52:118-121.

Juliani C. 2007. Field observations in the Rosa de Maio Project, Tapajós Gold Province (PA). Relatório inédito, 13 p.

Klein, E.L., Almeida, M.E., Vasquez, M.L., Bahia, R.B.C., Santos, M.L.E., Ferreira, A.L. 2001. Geologia e recursos minerais da Província Mineral do Tapajós. Folhas Vila Mamães Anã (SB.21-V-D), Jacareacanga (SB.21-Y-B), Caracol (SB.21-X-X), Vila Riozinho (SB.21-Z-A) e Rio Novo (SB.21-Z-C). Estados do Pará e Amazonas. Escala 1:500.000. Brasília: CPRM/DIEDIG/DEPAT, 2001, 81 p.

Kurimo, M. \& Multala, J. 1995. Aeromagnetic horizontal gradiometer system of the Geological Survey of Finland. Journal of Applied Geophysics, Abstracts, p. 139.

Lasa Engenharia e Prospecções S.A. 2006a. Levantamento aeromagnetométrico gradiométrico e aerogamaespectrométrico. Blocos Bandeirante, Maués e Doze de Outubro: relatório final de aquisição e processamento de dados. Volume 1. Textos técnicos e anexos. $41 \mathrm{p}$.

Lasa Engenharia e Prospecções S.A. 2006b. Levantamento aeromagnetométrico gradiométrico e aerogamaespectrométrico. Bloco Rosa de Maio: relatório final de aquisição e processamento de dados. Volume 1. Textos técnicos e anexos. $37 \mathrm{p}$.

McMullean, S.R.; MacLellan, W.H. 1997. Measured is better. In: Proceedings of Exploration 97: Fourth Decennial International Conference on Mineral Exploration, p. 873-876.

Minty B.R.S. 1991. Simple micro-levelling for aeromagnetic data. Exploration Geophysics, 22: 591-592.

Pinto M., Botelho N.F., Clerot L.C., Cunha L.M., Carrino T.A., Corrêa P.M. 2009. Geologia e geoquímica dos prospectos auríferos Doze de Outubro, Rosa de Maio, Bandeirante e Maués, Província Mineral do Tapajós, Amazonas. In: XI Simpósio de Geologia da Amazônia, 9: 2009, Manaus, Anais... Manaus: SBG, 2009, em CDROM.

Reford, S. 2006. Gradient enhancement of the total magnetic field. The leading Edge, 59-66.

Santos, J.O.S., Hartmann, L.A., McNaughton, N.J., Fletcher, I.R. 2002. Timing of mafic magmatism in the Tapajós Province (Brazil) and implications for the evolution of the Amazon Craton: evidence from baddeleyite and zircon U-Pb SHRIMP geochronology. Journal of South American Earth Sceinces, 15: 409-429. 
Schmidt, P.W., Clark D.A. 2006. The magnetic gradient tensor: its properties and uses in sources characterization. The Leading Edge, 75-78.

Telford, W.M., Geldart, L.P., Sheriff, R.E. 1990. Magnetic methods. In: Telford W.M., Geldart L.P., Sheriff R.E. (ed.)
Applied geophysics. Cambridge, Cambridge University Press, 62-135.

Thompson, S.; Fountain, D.; Watts, T. 2007. Airborne Geophysics - Evolution and Revolution. In: Proceedings of Exploration 07: Fifth Decennial International Conference on Mineral Exploration, p. 19-37.

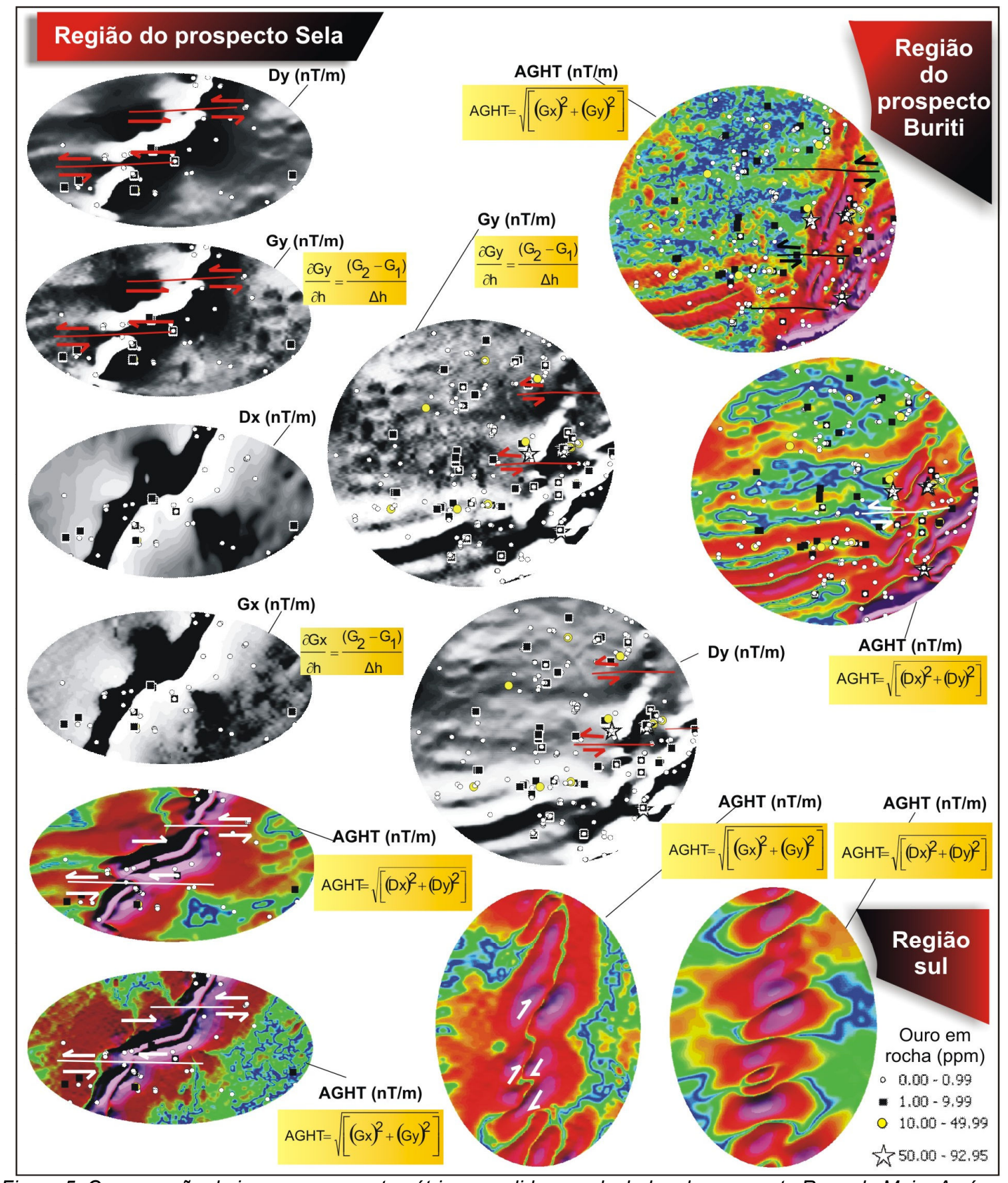

Figura 5. Comparação de imagens magnetométricas medidas e calculadas do prospecto Rosa de Maio. As áreas abrangidas estão indicadas na figura 4. Cores quentes indicam altos valores da AGHT; cores frias, baixos valores. As derivadas horizontais em $x$ e y estão representadas por Dx e Dy; os gradientes horizontais medidos nas direções $x$ e y estão indicados por Gx e Gy. 